\title{
Different Journeys: Supervisor Perspectives on Disciplinary Conceptual Threshold Crossings in Doctoral Learning
}

\author{
Gina Wisker \\ University of Brighton, University of Stellenbosch \\ Corresponding author: g.wisker@brighton.ac.uk
}

(Submitted 16 August 2018, accepted 6 December 2018)

\begin{abstract}
This article offers insights into supervisor awareness of conceptual threshold crossings in doctoral learning nuanced by researcher disciplines. First explored in undergraduate learning, threshold concepts highlight variation related to learning in the disciplines, identifying how realising the absolutely key concepts in disciplines causes troublesome and transformative learning (Meyer \& Land, 2005). Building on work on undergraduate disciplinary threshold concepts, but focusing on research learning, particularly at doctoral level, conceptual threshold crossings have been identified (Kiley \& Wisker, 2009), characterising significant stages in the learning journeys of doctoral candidates. At these stages, candidates evidence transformations in research learning. They cross-conceptual thresholds. There has to date, however, been little exploration of specific discipline-related stages at which doctoral candidates cross such conceptual thresholds. This new work focuses specifically on discipline-related practices and stages of conceptual threshold crossing in doctoral research learning and supervisors' awareness and support for work arising from this.
\end{abstract}

Keywords: doctoral learning, supervision, conceptual threshold crossings, threshold concepts disciplines

\section{Introduction}

The theory and practice of conceptual threshold crossing at postgraduate level grows from research on discipline-based threshold concepts in undergraduate research. It focuses on particular significant stages in a doctoral candidate's work when they make a shift or learning leap and work at a more complex, higher, conceptual, critical and creative level in their learning, accompanied by meta-learning (Flavell, 1979). In our earlier work, supervisors and doctoral candidates commented on both the signs of conceptual threshold crossing at stages of research, and ways in which certain practices 'supportively persuaded' development and 
awareness (Wisker et al., 2009). Our research on the 'doctoral learning journeys' project (Wisker et al., 2010) and beyond (Kiley \& Wisker, 2010; Wisker \& Kiley, 2009), additionally identified six generic research threshold concepts which characterise the processes and practices of that research, namely argument, theorising, framework, knowledge creation, analysis and interpretation, and paradigm.

New work reported here focuses specifically on doctoral supervisors and their awareness of, and support for, conceptual threshold crossings in the disciplines in relation to their own earlier doctoral work and that of their students. Supervisors have practical insights into research learning, and breakthroughs in that learning, and could use their insights to positively affect or supportively persuade conceptual threshold crossings in the work of their doctoral candidates (Wisker, 2010a). Research reported here uses active reflection in discussion workshops with supervisors engaged in supervising disciplinary or interdisciplinary research to draw out and identify doctoral supervisor awareness of (i) conceptual threshold crossings in different disciplines, at different stages in their own learning journeys, and those of their students, and (ii) what might help to supportively persuade such breakthroughs in learning to enable conceptual, critical and creative work in the research and thesis articulation of doctoral candidates.

The research uncovered awareness of learning breakthroughs, conceptual threshold crossings, at stages in the research journey, similarities and differences between disciplines sometimes in relation to the context of the research (Claesson \& Wisker, 2013), disciplineinflected ways in which research is undertaken, and ways in which disciplines construct knowledge. It offers new suggestions about breakthroughs and nuances in research practices, and aims to encourage supervisors to reflect on, share, and build on their own practice to support discipline-based conceptual threshold crossings.

\section{Threshold Concepts in the Literature}

During research into learning in the disciplines at undergraduate level, Meyer and Land (2003, 2005) identified what they defined as threshold concepts in disciplines, the absolutely essential concepts for understanding how knowledge is constructed and the world seen in a discipline. This built on David Perkins' work (Perkins et al., 2000). Some studies use threshold concepts as a basis to understand success or lack of it in their discipline, including Shanahan and Meyer's work (2006) on economics, where hitherto capable students either failed or scraped through first year exams. Shanahan and Meyer discovered less successful students exhibited a lack of awareness and comprehension of the essential threshold concepts in the discipline. They did not stop there and initiated curriculum changes, different teaching, learning, and assessment practices, offering development opportunities for students to grasp, understand, and practise the concepts, to understand more deeply, and creating and critiquing knowledge and arguments in the discipline. 
Threshold concepts have proved so compelling that academics across a broad range of disciplines and countries use them as a key to unblock misunderstandings and unlock the understanding and knowledge, ownership, and creation potential of students in their discipline. Threshold concepts are troublesome, as appreciating them disturbs hitherto established ways of thinking, but revelatory and enabling:

Akin to a portal, opening up a new and previously inaccessible way of thinking about something. It represents a transformed way of understanding, or interpreting, or viewing something without which the learner cannot progress.... (Meyer \& Land, 2003)

In Threshold Concepts in Practice (Land et al., 2016), the editors note that an 'uptake of the threshold concepts framework in some 249 subject areas in over 45 countries to date (Flanagan, 2016) has been both dynamic and gratifying' (Land et al., 2016: xii). Research on undergraduate threshold concepts is broad, focusing largely on disciplines exploring the transformational, troublesome nature of being stuck, forced to re-think one's knowledge and understanding of the discipline, and moments of breakthrough where the ontological sense of identity and being in the world shifts alongside a new epistemological grasp of how the discipline constructs knowledge, how it sees the world. Most excitingly, students who realise this begin to develop a sense of confidence, becoming co-constructors of knowledge in that discipline. As Glynis Cousin points out in her foreword (Land et al., 2016: ix), this shifts the focus from student satisfaction to students as contributors of knowledge, and is empowering, beyond a passive reception, customer satisfaction model. A significant issue here, I would argue, is the identifying of learning as a form of research, based in developing understanding, ownership, confidence, and creation of something nuanced or new. Work in the disciplines focusing on threshold concepts (Land et al., 2008; Flanagan, 2016) highlights this change in approach to learning, while introducing examples of practical steps to make the context more likely to support and enable acquisition of threshold concepts and their effect on learning. Opportunities for threshold concept-informed undergraduate research learning to take place are often through curriculum change, and learning, teaching, and assessment practices enabling breakthroughs in learning.

Work on threshold concepts at doctoral level is limited, although Keefer $(2013,2015)$ and Carter (2016) each consider moments of liminality, confusion, potential, and breakthroughs in learning leading to transformation of doctoral identity, quality, and kind of research learning. Keefer notes:

Doctoral learning frequently involves a shift during the postgraduate journey where change occurs, with researchers experiencing a new way of seeing their understanding or place within the area study (Trafford \& Leshem, 2009). This altered identity often comes 
after a liminal period of uncertainty, confusion, or doubt, something akin to the transition within a rite of passage (Turner, 2011; van Gennep, 1960). Easily lost in this shuffle while identifying doctoral thresholds are the experiences of the learners themselves. (Keefer, 2010: 15, 17)

Internationally, doctoral programs increasingly teach courses to support informed engagement with research methods, and the research and writing of the thesis. While programmes are often generic, encouraging research thinking, choice of methodology and methods, and sound writing practices, doctoral candidates are essentially also on a learning journey which requires that they understand and can put into practice discipline or interdiscipline-related (since many $\mathrm{PhDs}$ are interdisciplinary or relate theory to professional practice) research and knowledge creation. This is based on their understanding, mobilisation of, and ability to articulate something new, a contribution to knowledge usually in their discipline/interdisciplinary area.

\section{Early Research Work: Doctoral Learning Journeys and Beyond}

Wisker, Kiley, Robinson, Trafford and Leshem identified threshold concepts and conceptual thresholds at the research education level (EARLI, 2007; QPR, 2006; Threshold Concepts conferences, 2006, 2008; Wisker et al., 2008). Our research work on conceptual threshold crossing in doctoral learning journeys grew from threshold concepts in the disciplines at undergraduate level, and focuses on research learning, both disciplinary and interdisciplinary. We developed the notion of conceptual threshold crossings to identify significant moments and stages in their work when doctoral candidates make learning leaps and begin to work in more conceptual, critical and creative ways. We found students and supervisors are aware there are some specific moments where the demands of the research and writing work can be seen to offer opportunities, for more conceptual, creative and critical perspectives, research and expression in writing and/or presentations. Evidence of doctoral student, supervisor, and examiner awareness of conceptual threshold crossings emerged during interviews for the doctoral learning journeys (2007-2010) research (UK-based), the parallel project (internationally based), and then the project in Sweden (Claesson and Wisker, 2013), which included medical and other scientists, as well as the humanities and social sciences, the focus of the two previous projects.

The doctoral learning journeys project involved a survey (350 doctoral candidates), and journaling and narrative interviews (30 down to 20 students over 3 years, interviews with 20 supervisors and 11 examiners). The parallel project focused entirely on interviewing students, supervisors, and examiners internationally; none were scientists in either project. The Swedish project involved interviewing 40 postgraduate students and supervisors (including scientists and medical scientists). This range of work offered evidence that there are particular stages in a 
doctoral candidate's work when they make a shift or learning leap and work at a more complex, conceptual, critical, and creative level in their research learning, accompanied by meta-learning (Flavell, 1979), and that many supervisors also perceive this shift and, when asked, can offer suggestions of how to enable or support it.

This earlier work did not actively explore the disciplinary focus of conceptual threshold crossing, i.e. stages in the research learning of particular disciplines at doctoral level which could lead to learning leaps, opening up new ways of understanding and creating knowledge in that discipline. However, discussing conceptual threshold crossings with supervisors during international workshops on supervision (2008-2016) revealed some interesting initial awareness, based in their own experiences of how the nature of learning and research in their discipline affected the learning journey and likelihoods of moments of breakthroughs or conceptual threshold crossings. I used these discussions to develop a research plan to build on personal learning insights the workshop participants offered: first of an understanding of threshold concepts in their own discipline, then of moments where they have become aware of crossing conceptual thresholds in their own research learning, an awareness of breakthroughs in stages of their research learning and what helped supportively persuade these into being. Following this, I was interested in how they felt they could transfer such insights about their own conceptual threshold crossing experiences to inform their work with doctoral candidates.

It is an (unproven) assumption that upon embarking on the doctorate, doctoral research students have already gained threshold concepts in their discipline or inter-disciplines. Although there is no specific test for this, the maturity of their work in the discipline suggests this is the case. For doctoral work it is also desirable, perhaps essential, that they cross conceptual thresholds in their work and contribute to knowledge. However, some of our early work informed by examiner definitions of a 'less than ideal' thesis (Mullins \& Kiley, 2002) suggested that breakthroughs in understanding and knowledge, learning leaps, might not be essential for the merely 'good enough' (Wisker, 2010b) thesis, and in the research, which contributed little more than factual information. One might argue this is not enough for a $\mathrm{PhD}$, but supervisors in the recent work were divided, and often along disciplines. For some students, which our participants discussed, few, if any, thresholds have been crossed, producing work which is just 'good enough'. For Kiley and Mullins (2002), concerning examiner expectations, this would probably evidence a lack of significance, risk-taking, overall coherence, and clear sense of contribution.

Research based on the responses of supervisors in workshops in Sweden (2011-2013) elicited a preference for cross-disciplinary discussion and development, which surfaced some of the disciplinary differences in supervision of doctoral learning, as well as generic issues and achievements. The supervisors' comments in our earlier work (Claesson \& Wisker, 2013) relate to supervision in a disciplinary context with three main results indicating difference:

- Working in a team versus individual ability, and expected to read, analyse and write; 
- Working in a team versus studying alone; and

- $\quad$ Formulating own research questions versus taking part in an established project.

Supervisors continued to elaborate on the different contexts in which doctoral research took place, and different approaches in the disciplines. In the earlier work, we did not ask them to consider conceptual threshold crossing stages in relation to doctoral learning and supervision practices in the disciplines. Our new work focuses on the issue of supervision practices in the disciplines.

\section{Methodology and Methods}

This new research with doctoral supervisors (Sweden, South Africa, UK, 2013-2017) is both deductive and inductive. It builds on earlier, ongoing work (Wisker et al., 2010), which identified significant stages in the learning journeys of doctoral candidates at which they crossed conceptual thresholds (Kiley \& Wisker, 2010; Kiley \& Wisker, 2009), beginning to work research and write - in more conceptual, creative, and critical ways suitable for PhD success, as defined by colleagues, focusing on doctorateness (Trafford \& Leshem, 2008) and examination (Kiley \& Mullins, 2002).

Work with supervisors in the international supervisor development workshops which I facilitate or co-facilitate aims to elicit reflection and the sharing of experience and knowledge. Workshops are frequently used in educational or academic development to develop ideas and knowledge (Baume \& Kahn, 2004; Baume \& Popovic, 2016; Edwards et al., 2003) and reflection (Schon, 1983), and are particularly useful as a developmental mechanism to enable supervisors to enhance their practice (Brew \& Peseta, 2004). The supervisor workshop setting encourages reflection, dialogue, contestation, and the development of shared understanding (even where disagreement might remain). Further work could focus on the dynamic interaction across disciplines, and on the efficacy of specific support practices in different disciplines.

This qualitative research is based on short responses formally produced as part of the workshop process with supervisors in Sweden, Republic of Ireland, UK and South Africa (20132017; approx 200 supervisors). It is not action research (it does not follow participants' reflections and actions over time) nor ethnographic (it does not seek long narratives). Nor is it grounded in theory, since we shared both understanding of threshold concepts and conceptual threshold crossings in advance, and signalled in discussions to consider when, if, how, and in what ways any breakthroughs in learning and understanding took place. Rather, the reporting back on the discussion questions (see below, questions for which I sought responses and on which this research is focused) grew naturally from the discussion format.

The research was ethically approved appropriately at the University of Brighton as part of my research on doctoral supervision, and informed consent was received from participants at the start of the workshop process section focusing on threshold concepts and conceptual 
threshold crossings. Workshop participants decided individually whether their formal reporting back could be recorded and used for the research or whether they would report back in the normal way from group discussions and not be taped. Those who did not want to be recorded did not have their comments included as research data. Data is held securely on password protected PC.

As part of developmental work, supervisors and the participants in the workshops discussed their own experiences and those of their students. Following informed discussion about threshold concepts (Meyer \& Land, 2003, 2005) and conceptual threshold crossings in doctoral research (Wisker et al., 2010), the supervisors and workshop participants were asked to consider and identify specific moments when they had 'learning leaps', crossing conceptual thresholds, in their own research learning journeys. The published research emphasises difference between those smaller everyday moments of clarification and understanding, and significant moments when transformed ways of seeing, understanding, and contributing to the research become clear. Participants focused on events leading to these conceptual threshold crossings, how they knew their work had shifted into this new conceptual quality, what the signs were, if they had experienced any liminal moments of transition before this new level of understanding, how and if the terms of transformation, integratedness, troublesomeness, irreversibility, and boundedness were experienced in the attainment of this new understanding, and how all or any of these are experienced and expressed in their own discipline. They were also asked to consider such moments in the research learning of their students. This part of the work is deductive. Theories were shared, and specific questions asked about identified stages.

Reporting from supervisors enabled clarification, reflection, focusing and sharing. The point of workshop work and reporting for the research was to surface and clarify realisations about the nature of breakthroughs in understanding, in order to learn from each other and share good practice among (i) the group, and later (ii) others reading the research findings. Participants and readers can build on insights into the nature of disciplinary and interdisciplinary conceptual threshold crossings and suggest supportive practices for their own practice. I used the research-informed, guided interactive dialogue and discussion nature of the mixed discipline supervisory workshop format to engage supervisors with articulating and defining the differences (and similarities) in the conceptual threshold crossing breakthroughs in their own and their students' research learning, using the workshop mode to articulate understanding emerging from reflection and discussion.

I first sought awareness of information on and use of threshold concepts, and then of conceptual threshold crossings through asking the supervisors about (i) recognising and/or remembering breakthroughs in learning in their own work as doctoral candidates, and what helped enable these breakthroughs; (ii) recognising, remembering, and identifying such moments of conceptual threshold crossing in the work of their doctoral candidates when actively working with them or reading their work and hearing their work presented; and (iii) their 
awareness of what helped supportively persuade such crossings into being. I sought consideration of and answers to the following questions:

1. What do supervisors working in different disciplines remember and understand of their own realisation of threshold concepts, and of conceptual threshold crossings during their doctoral learning journeys?

2. Do these differ and if so, how do these differ between different disciplines?

3. What do supervisors identify concerning threshold concepts and conceptual threshold crossings in the learning journeys of their doctoral candidates?

4. What supportively persuaded their own and their students' achievement of threshold concepts and conceptual threshold crossings?

5. How might they supportively persuade their students' achievement of threshold concepts and conceptual threshold crossings?

\section{Threshold Concepts and Beyond Analysis and Findings}

Responses were taped, transcribed, number labelled, and thematically analysed. Braun and Clarke (2006: 79) define thematic analysis as: 'A method for identifying, analyzing and reporting patterns within data'. The analysis was conducted through reading and re-reading until themes and sub-themes began to emerge and new themes and issues were exhausted. Excerpts in transcripts were colour coded to identify themes. Sub-themes were synthesised into several main themes and the whole read through again to see if any other issues and themes emerged. The text-based interview data was organised into tables in Microsoft Word ${ }^{\mathrm{TM}}$. Other responses emerged (inductive), which highlighted further themes and issues. Findings from both deductive and inductive work are reported below.

When asked, the supervisors identified threshold concepts, indicated how they used them in research learning but then started to move beyond them, considering their limitations. Following this, I asked them about stages in the research, and they identified developments, conceptual threshold crossings at different stages, and moved beyond that. Supervisors offered examples of moments and practices which moved them beyond being stuck in their research thinking, challenged frameworks as limiting research discoveries, and brought in contestation and different theories and practices from other disciplines, or other advances to open up their work and its contributions to original knowledge or ways of going about research.

\section{Threshold Concepts as a Model to Enable Understanding in the Sciences}

The scientists in the supervisor workshops in particular offered interesting examples of ways in which they worked with threshold concepts in their research learning and in the lab. Their questioning of threshold concepts as openings to and frameworks for understanding show breakthroughs in their thinking beyond the initially enabling frameworks the threshold concepts 
offered. They emphasised the need to theorise, find models, systems, and a shared conceptual language for the structure within which questions might be asked, and what was found, comprehended and communicated. Simultaneously, they emphasised the tentative, artificial nature of models, hypotheses, grids, and concepts, noting that experiences and results are all less amenable to categorisation and slip away from it. The learning trajectory is one of constant questioning and testing, even of what is used as a bedrock of theory and understanding, in one case Newton's law. Framework and theorising interact in the examples that follow.

\section{Psychiatry}

This response indicates the tenuousness of labels and concepts and also suggests that in understanding that your discipline is complexly rich with related influences and impossible to fully understand, to close down, is in itself a threshold concept:

I think as soon as I think I understand the threshold concept of psychiatry I don't understand it any more because we have these diagnostic systems in psychiatry and we're trying to classify different conditions and function impairment to give it a name but then we don't really understand the biology behind it, so we have lot of overlapping systems and you can have different biological background to the same conditions and it's really hard to find a good system so as soon as you think you have understood it you will discover that you don't really grasp it. $(P)$

\section{Science and Maths}

In science and maths, we invent threshold concepts as a language to communicate and then we spend a lot of time testing to see if those always hold up under scrutiny, so even like Newton's laws are threshold concepts we have to understand, or the zero, first and second law of thermo-dynamics are. These are concepts that do work in certain field you have to grasp and be able to communicate about, but we're always also testing them because they're never fact, they are constantly being tested, the fundamental theorem of calculus, for example. (B)

\section{Stages, Disciplines, and Supportively Persuading: Supervisor Experiences and Views}

Threshold concepts, first identified in undergraduate learning, are essential concepts which open up understanding about how a discipline sees the world and constructs knowledge. The moment when doctoral researchers understand how their discipline constructs knowledge and see the world in terms of their research project (realising threshold concepts in discipline learning in action) is a crucial breakthrough stage in their learning as a researcher. So too are 
the moments of thinking beyond the (helpful) bounds of threshold concepts themselves, as illustrated above. Such moments of understanding, of the concepts, and of their limitations can be seen as conceptual threshold crossings because they reveal new, complex, transformed meaning.

Conceptual threshold crossings are crucial, as doctoral researchers need to make leaps in their understanding of their research process, discovery, creation and its contribution at significant stages in that research journey (Kiley \& Wisker, 2009), essential for PhD success, doctorateness (Trafford \& Leshem, 2008) and examination (Mullins \& Kiley, 2002). To date, there has not been a focus on conceptual threshold crossings which might relate to/derive from the nature of the discipline. What this research sought was supervisor awareness in their own research journey and that of their students, of such conceptual threshold crossings at significant stages in their journey, related to their disciplines. The work was both deductive, checking awareness of conceptual threshold crossings at stages in the research, and inductive, exploring if there were discipline-specific conceptual threshold crossings affected by the nature of the discipline and ways it is researched.

I next focus on these stages when conceptual threshold crossings are likely to take place, which are: i) asking research questions/actioning hypotheses; ii) literature reviewing and developing a dialogue with the literature; iii) developing and actioning methodology and methods; iv) analysing data and developing discussion; and v) producing conclusions.

This is nuanced by our earlier research (Kiley \& Wisker, 2009), which focuses more on the conceptual, theorised work undertaken throughout, particularly in stages (i) and (ii) the argument, theorising, framework, and (iv), (v) knowledge creation, analysis and interpretation, and paradigm.

First, I deal with differences and similarities in the disciplines in the significant stages as they emerged in the data, emphasising the unexpected similarities or differences between disciplines.

\section{Research Question/Hypothesis - Stage}

In earlier work (Wisker et al., 2010), several stages, standard in doctoral research projects, emerged as enabling different forms of thinking and engaging with the research, which could supportively persuade conceptual, critical, and creative work. The moment of developing a research question was seen as significant in 'nudging' conceptual levels of thinking and working, starting the process of framework and knowledge creation. Participants discussed such moments, speaking also of asking questions throughout the research as a way of prompting the learning, where using different frames for asking different questions emerged as significant opportunities for conceptual threshold crossings. 


\section{Science Project}

Supervisors argued that even when taking a small slice of a larger science project, there needs to be a research question and a conceptual framework to deepen the project for the student, so they develop their own framework and knowledge creation, moving beyond given patterns of questioning to asking their own.

There will be a topic that is defined as part of a larger project, there will be the conceptual framework and they actually argue there is one. (A)

\section{Neurology}

Patterns of questioning are set up and repeated, then new questions arise leading to new ways of thinking.

You do internalise a way or a pattern of questioning. I say, 'well if you look at it this way could it be used on that receptor for example', he says, 'ahh okay.' It's like challenge them, so they find stuff. Usually after a couple of weeks they are pretty self-confident and then they come asking questions. And then I learn. (I)

\section{Medieval Logic}

Repetition, patterns, then new insights could be seen as a scientific way of progressing research; however, other disciplines reported similar processes. For medieval logic, insightful questioning challenged and upset established patterns, providing new patterns and frameworks to address questions:

I think the most important threshold crossing I have had so far is when I started with the intuition during my $\mathrm{PhD}$ that the way we were analysing medieval and ancient logic was wrong because we were using the wrong framework, we were using formal contemporary logic and then it just didn't work, what I was doing just didn't fit... I realised that actually the most important part of ancient and medieval logic is the non-formal aspects and that's also what motivated their development and that's where I'm going now, but it had been hard because it's defying a tradition that is like 50 years old. (K)

\section{Methodology, Methods and Carrying Out the Research - Stage}

Deciding on methodology and methods is a key moment, as is fieldwork, data gathering and creation. While each discipline supervisor discussed methodology and methods as a framework to help address questions or explore and test hypotheses, they were also aware that the methodology and methods chosen affected what could be explored, and the mode of questioning affected the responses and subsequently what could be created, found and 
understood. Moments of making decisions about methodology and methods and their practice through the project support ownership. Supervisors spoke of themselves and ways to supportively persuade students to make decisions, put methods into practice, and develop confidence and ownership.

\section{Science}

Methodology would be selected, all of that will be in place and then the student will start to implement one aspect of it. Now l've heard colleagues say that the more able students will be the ones who will do the first two experiments as per instructions and then go 'oh no hang on a minute it needs to go in this direction', and they will say 'yes good that's really promising', and then they do develop those independent skills a bit later. (A)

Revisiting as well as the going forward but it's now kind of coherent movement. That's one of the conceptual leaps that I think people need to make. (A)

The development of independent decision-making and skills is recognised here in science students as an indication of the tenuousness of essential understandings, insights, and confidence that come with conceptual threshold crossings. They learn to revisit, re-question, retry and build and confirm their understanding. Working with projects in science offers opportunities to achieve conceptual threshold crossings when developing independent skills, revisiting, then trying something new and moving forwards.

Realising the tenuous and temporary nature of any theory, framework, or fixed interpretation was seen to be at the heart of the way in which research learning itself takes place in these disciplines, so that independent students move on from the scheme of work they are given and test the established. This concurs with Mullins and Kiley's (2002) risk-taking, a sense of being open to knowledge (without it being overwhelming) and responsive to guidance (without it being a straitjacket).

Some disciplines construct knowledge 'bottom up', i.e. beginning with hands on experiential work.

Computer Science and Software Engineering - Encouraging Research Learning Bottom Up

Software engineering and computer science .... If you try to hammer it as top down approach, learn this and that, and that it's extremely complex and then you go down it's getting even more complex. I think it's better when you start bottom up. When you really do some hands-on work in some very concrete instances and then think about and slowly develop some specific problems and only learn those things that you need to learn for 
solving these problems, otherwise you get lost and you don't have a concrete scope and focus. $(P)$

One neuroscientist commented that patience and dedication are essential:

I can get an idea especially in the beginning, for example, and then I have to test the idea and the testing might take 6 years to do the testing of just one breakthrough idea. $(\mathrm{N})$

Mixed groups of supervisors reflecting on their own research learning and the conceptual threshold crossings in their and others' work fed into their received and experienced ideas of the sciences or social sciences, in discussion, and helped clarify their own beliefs on behaviours regarding research. Testing and repeating were not seen as necessary research practices in social sciences, and there was widespread awareness that theory and perspective both enabled and constricted questioning and interpretation seen as a lens rather than 'reality'. Social science supervisors in particular seemed to be using theory as a jumping off point for research questions, although the theories will in the main have been derived from real life incidents and issues.

Social scientists had certain views about how disciplinary knowledge was constructed in the sciences:

So we thought that in a science in which the belief is in accumulation based on previous ideas and you repeat sometimes, or kind of refine a bigger idea, then you can look ... but in a science like social science where there is not really an accumulation you don't really build on previous, you don't really believe in this progress, then these threshold crossings might look in a different way and might be maybe more often and you don't need to test. (D)

Specific research behaviours associated with certain disciplines can enable breakthroughs in thinking and understanding where some of the work is planned and systematised. Some research is less possible to plan. An ethnographer in anthropology talks of finding the undetected through patience and presentness.

\section{Anthropology}

I normally do some research and it's some anthropology and additional systems and it's interesting where you find information or where you find a breakthrough - sometimes in the place you really don't expect or in the most remote of places; someone is sitting in a hut and they have nothing and they tell you things that you didn't expect to hear. (E) 
Breakthroughs in both anthropology and ethnographic research were discovered by immersing themselves in the research location - the village - and being patient. This is related to the ways in which this discipline develops knowledge.

\section{Data Analysis and Interpretation of Findings Using Theory - Stage}

Across the disciplines the analysis of the data was seen as a phase which could enable breakthroughs in thinking, and conceptual threshold crossings, since it is an intensely focused period applying theory and identifying themes and findings emerging from data analysis and interpretation. One of the social science discussions considered the importance of using theories, frameworks, and methodology to act as systems to enable understanding knowledge creation and interpretation.

\section{Social Science}

Supervisor participants discussed their awareness of conceptual threshold crossings, offering new knowledge. Practices and strategies seen to supportively persuade or enable conceptual threshold crossings at different stages in the research learning journey include both engaging, manipulating with technology and technology advances, and stepping back, away from the work, to see patterns, refocus. 'Discovering constructivism' is how one supervisor characterised the process construction of patterns to enable interpretation:

I think one key thing is social constructivism ... so it's not just the phenomena as it is but that there is some systemic order behind it. $(G)$

\section{Identifying Patterns}

One important stage in the analysis of data is that which enables breakthroughs in learning related to patience and 'seeing the wood for the trees'. This includes the importance of sitting with any data and letting patterns emerge through revisiting (science and social science) or sitting with people until the discussion and questioning produce insights (anthropology). Systems, patterns and theories as constructions, cyphers and analogues were seen as useful in drawing interpretations and findings from analysed data. For comprehension, 'making sense' was also a common feature, where becoming aware of these structures and systems which enabled clarification of themes, patterns, modes of interpretation, was both a way of managing the understanding and letting it reveal itself, and yet potentially a superficial overlay on the complexity.

Things about data analysis being an important moment for having new ideas. At least it was for me doing my PhD, I just sat with the data. Tried to explain the data which was interesting. $(\mathrm{H})$ 
Moving Beyond the Stages: Tech advances, Thinking Creatively, Walking Away

Considering the enabling of stages of the research led supervisor participants next to move outside the frame of the research project itself and offer examples of conceptual threshold crossings enabled by technology advances, or activities other than the research, or thinking outside the box by using creative analogies and metaphors. Breakthroughs can also take place when not writing/in the lab but in a park, walking, sitting and thinking, in the countryside.

\section{Tech Advances}

In some disciplines, both data analysis and interpretation are enabled through technology, e.g. NVivo, which also requires categories and themes to be suggested (before others might emerge), and re-reading, re-scrutinising until patterns emerge and 'outliers', noting variation - a key to a breakthrough.

We talked also about technologies and methods that can trigger a threshold crossing. So, for example you know if you change technology or new one is invented and then they have crossing that they couldn't have had before but also if you take it to another field if you do things in a different way. $(\mathrm{J})$

\section{Doing Something Else - Thinking Creatively}

Focusing on issues not related to the research and then researching outside the field were seen by these supervisors as ways of opening up new perspectives and thought patterns:

Yes, $\mathrm{X}$ and I were more visual, we like making diagrams and organising and having blanks that we will then mull over but both of us also like to leave it alone and go off and do something else whether it's gardening or cooking or ... (Q)

And the other one is reading outside the field and sometimes reading that's actually nothing to do with what you're looking at, or watching TV actually, nothing to do with what you're looking but the idea is just like a computer screen, your mind is still thinking about these issues and you are going, 'oh that's it I've got an analogy', or they've said something that brings light on what I'm doing. $(\mathrm{N})$

Yeah and half my students now talk about this habit, when stuck go and look outside of the field. $(X)$ 
Free talking, like free writing, was also seen as a way of opening up thinking leading to conceptual threshold crossing:

Free talking with other people - even if they are not experts in the field they might just be interested - you just talk to them they might not even be listening but you are saying it, talking about it and yacking away and all of a sudden you actually get the argument through talking it through out loud. (Z)

You might say "so what does that mean? so what will you do next?", so the prompting from the free talk will cause the breakthrough. (Q)

These new ideas emerged beyond the prompted questions about disciplines or stages.

\section{Conclusions}

Conceptual threshold crossings largely concern stages in research learning when doctoral candidates make breakthroughs in their thinking, understanding, researching and writing. At these points they show both ontological change - change in the way they see themselves in the world and in identity as a research learner - and epistemological change: a confidence in engaging with the research learning, and an active awareness of the ways of constructing knowledge and making a contribution. Their work is (more) conceptual, critical, and creative. The research helped identify discipline and culture inflections and differences (Trowler et al., 2012) related to perspective, research practices, contexts, ways of seeing, writing practices, what counts as knowledge.

The data produced from the supervisor workshop discussions offers many suggestions for the moments when conceptual threshold crossing can take place. Some are generic, related to stages, some quite discipline-specific, and some emerged unprompted from outside these frameworks.

Insights in this new work are based on using workshop dialogue and knowledge creation work to elicit supervisors' own perceptions, and their intended or current practices to supportively persuade the breakthroughs in learning among students. This it does by building on their awareness of their own achievement of threshold concepts in their discipline/interdisciplines, and crossing conceptual thresholds at stages of their own doctoral work; recognising the characteristics in their own disciplines of research learning that enable breakthroughs in thinking; developing their awareness of the transitions and transformations in the work of doctoral candidates; and realising ways in which they can supportively persuade such achievements and transformations. Sharing through dialogue in mixed disciplinary supervisor workshops has itself supportively persuaded that awareness among supervisors in 
the different disciplines. There is a range of approaches and attitudes which emerged as important. Some of the characteristics which enable conceptual threshold crossings in the sciences, according to the data analysed from the participants' responses (a selection above), include: repetition, asking questions a new way, breakthroughs after repetition and patterns of questions and thinking, testing and accumulation, using new technology, opening up new ways to ask questions, and sitting with the data and analysing/re analysing it. The findings offer rich and useful insights into the widespread nature of conceptual threshold crossings involving generic research and threshold concepts of argument, theorising, framework, knowledge creation, analysis and interpretation, and paradigm, at different stages in the research journey, often in different ways in different disciplines, and often in some similar ways. They also suggest different catalysts and practices, including supervisors who can initiate such crossings, and how similar or different they are in different disciplines.

Specific activities, engineered accidents, surprise moments, and deliberately walking away from the work to let it settle, re-shape, were identified as causing breakthroughs. Opening some of these out a little more we see how the breakthroughs happen, and so the moments when supervisors could supportively persuade the work by making opportunities to develop and share available, engaging in dialogue, setting up opportunities to disseminate and share, using prompt questions and suggestions for reading.

A reason for engaging the supervisors in the workshop dialogues was so that they could surface, articulate and share their own experiences and those of their students, where they had seen, heard and read them. An unexpected result was the ways in which, together, they generated really lively, vital new thinking, knowledge and insights about not placing patterns onto students, but enabling them to question, develop their own insights, query others, and how breakthroughs took place by not focusing hard on it: by leaving the work to settle, or developing analogies from other contexts. Supervisors offered examples of good practice in helping to supportively persuade students to cross conceptual thresholds in their work. However, they voiced a cautionary note:

I think there's one thing I think is very important and powerful question that we need to ask all of ourselves, is that we don't place our own map of coherency onto our students. (L)

\section{Author Biography}

Gina Wisker is Head of the University of Brighton's Centre for Learning and Teaching, Professor of Higher Education and Contemporary Literature, where she teaches and researches in learning, teaching, postgraduate study supervision and academic writing. With 25 books (some edited) and over 140 articles published, works include: The Postgraduate Research Handbook (2001, 2008), The Good Supervisor (2005, 2012) and Getting Published (2015). Gina also specialises in twentieth-century women's writing, postcolonial, Gothic \& popular fictions, see: 
Key Concepts in Postcolonial Writing (2007), Horror (2005), Margaret Atwood: An Introduction to Critical Views of Her Fiction (2012) and Contemporary Women's Gothic Fiction (2016). Gina has supervised $31 \mathrm{PhD}$ students to completion and examined 42. She chaired the Heads of Education Development Group, SEDA Scholarship and Research committee, and the Contemporary Women's Writing Association, is on the Society for Research into Higher Education Council, and is chief editor of the SEDA journal Innovations in Education and Teaching International, dark fantasy online journal Dissections, and poetry magazine Spokes. Gina is an HEA Principal Fellow, National Teaching Fellow \& SFSEDA.

\section{References}

Baume, D. \& Kahn, P. 2004. Enhancing Staff and Educational Development. New York: Taylor \& Francis.

Baume, D. \& Popovic, C. (Eds.). 2016. Advancing Practice in Academic Development. London: Routledge Staff and Educational Development Series.

Braun, V. \& Clarke, V. 2006. Using thematic analysis in psychology. Qualitative Research in Psychology, 3: 77-101.

Brew, A. \& Peseta, T. 2004. Changing postgraduate supervision practice. Innovations in Education and Teaching International, 41 (1): 5-22.

Carter, S. 2016. Supervision learning as conceptual threshold crossing: when supervision gets 'medieval'. Higher Education Research \& Development, 35 (6): 1139-1152.

Claesson, S. \& Wisker, G. 2013. The impact of cross-disciplinary culture on student-supervisor perceptions. International Journal of Doctoral Studies, 8: 21-37.

Edwards, H., Baume, D. \& Webb, G. (Eds.). 2003. Staff and educational development: Case studies, experience, and practice from higher education. London: Kogan Page.

Flanagan, M. 2016. Threshold concepts: undergraduate teaching, postgraduate training, professional development and school education. http://www.ee.ucl.ac.uk/ mflanaga/thresholds.html

Flavell, J.H. 1979. Metacognition and cognitive monitoring: a new area of cognitivedevelopmental inquiry. American Psychologist, 34: 906-911.

Keefer, J.M. 2010. Public transformations: adult learners who use social media to express and understand their identities as developing researchers. Presented the Internet Research 11: The 11th annual conference of the Association of Internet Researchers (AoIR), Gothenburg, Sweden. October 2010.

Keefer, J.M. 2013. Navigating Liminality: The experience of troublesome periods and distance during doctoral study. Unpublished PhD diss., (M. Tight.), Lancaster University, Lancaster, UK.

Keefer, J.M. 2015. Experiencing doctoral liminality as a conceptual threshold and how supervisors can use it. Innovations in Education and Teaching International, 52 (1): 17-28. 
Kiley, M., Mullins, G.P. \& University of Canberra. 2002. Quality in postgraduate research conference, and the Centre for the Enhancement of Learning, Teaching and Scholarship, in Kiley, M. \& Mullins, G. (Eds.). Quality in Postgraduate Research: Integrating Perspectives. Electronic resource.

Kiley, M. \& Wisker, G. 2009. Threshold concepts in research education and evidence of threshold crossing. Higher Education Research and Development, 28 (4): 431-441.

Kiley, M. \& Wisker, G. 2010. Learning to be a researcher: the concepts and crossings, in Land, R., Meyer, J.H.F. \& Baillie, C. (Eds.). Threshold Concepts and Transformational Learning. Rotterdam: Sense Publishers, 399-414.

Land, R., Meyer, J.H.F. \& Flanagan, M.T. 2016. Threshold Concepts in Practice. Rotterdam: Sense Publishers.

Land, R., Meyer, J.H.F. \& Smith, J. (Eds.). 2008. Threshold Concepts Within the Disciplines. Rotterdam: Sense Publishers.

Meyer, J.H.F. \& Land, R. (Eds.). 2003. Overcoming Barriers to Student Understanding: Threshold concepts and troublesome knowledge. London/ New York: Routledge.

Meyer, J.H.F. \& Land, R. 2005. Threshold concepts and troublesome knowledge (2): epistemological considerations and a conceptual framework for teaching and learning. Higher Education, 49: 373-88.

Mullins, G. \& Kiley, M. 2002. 'It's a PhD, not a Nobel prize': how experienced examiners assess research theses. Studies in Higher Education, 27 (4): 369-386.

Perkins, D., Tishman, S., Ritchhart, R., Donis, K. \& Andrade, A. 2000. Intelligence in the wild: A dispositional view of intellectual traits. Educational Psychology Review, 12 (3): 269-93.

Schön, D.A. 1983. The Reflective Practitioner: How professionals think in action. New York: Basic Books.

Shanahan, M. \& Meyer, J.H.F. 2006. The troublesome nature of a threshold concept in economics, in Meyer, J.H.F. \& Land, R. (Eds.). Overcoming barriers to student understanding: Threshold concepts and troublesome knowledge. London/New York: Routledge, 100-14.

Trafford, V. \& Leshem, S. 2008. Stepping stones to achieving your doctorate: By focusing on your viva from the start. Maidenhead: Open University Press.

Trafford, V. \& Leshem, S. 2009. Doctorateness as a threshold concept. Innovations in Education and Teaching International, 46 (3): 305-316.

Trowler, P., Saunders, M. \& Bamber, V. 2012. Tribes and Territories in the 21st-century: Rethinking the significance of disciplines in higher education. Abingdon and New York: Routledge.

Turner, V. 2011. The Ritual Process: Structure and anti-structure. New Brunswick, NJ: Aldine Transaction Press.

van Gennep, A. 1960. The Rites of Passage. Chicago, IL: University of Chicago Press. 
Wisker, G. 2010a. 'Nudging': exploring effective strategies to enable postgraduate research students to cross conceptual thresholds in their doctoral work. Paper presented at third Threshold Concepts symposium, Sydney, Australia. 1-2 July 2010.

Wisker, G. 2010b. The good enough doctorate: doctoral learning journeys. Acta Academica: Postgraduate supervision: research and practice, Supplementum 1: 223-242.

Wisker, G., Morris, C., Warnes, M., Lilly, J., Robinson, G., Trafford, V. \& Cheng, M. 2009. Doctoral learning journeys: supporting and enhancing doctoral students' research and related skills development through research evidence-based practices. Assessment, Learning \& Teaching Journal, 5: 19-22.

Wisker, G., Morris, C., Cheng, M., Masika, R., Warnes, M., Lilly, J., Trafford, V. \& Robinson, G. 2010. Doctoral learning journeys - final report of the NTFS-funded project. http://www.heacademy.ac.uk/resources/detail/ntfs/projects/doctoral_learning_journeys

Wisker, G., Robinson, G. \& Kiley, M. 2008. Crossing liminal spaces: encouraging postgraduate students to cross conceptual thresholds and achieve threshold concepts in their research, in Kiley, M. \& Mullins, G. (Eds.). Quality in postgraduate research: research education in the new global environment - part 2: conference proceedings. Canberra: CEDAM, ANU.

\section{Websites on Threshold Concepts}

https://www.ee.ucl.ac.uk/ mflanaga/thresholds.html

ETL project. http://www.etl.tla.ed.ac.uk/publications.html 